\title{
AUDIT SISTEM PEMBANGKIT TENAGA SURYA DI PULAU SABIRA -JAKARTA
}

\author{
${ }^{1}$ Bayu Prabowo, ${ }^{2}$ Muhammad Rif'an, ${ }^{3}$ Massus Subekti \\ 1,2,3 Pendidikan Teknik Elektro, Fakultas Teknik, Universitas Negeri Jakarta \\ 1,2,3 Email : bayuprabowo294@gmail.com ; m.rifan@yahoo.co.id ; masus@unj.ac.id
}

\begin{abstract}
The purpose of this study was to study the non-optimal causal factors and the work system of PLTS $15 \mathrm{kWp}$ as a power plant on Sabira Island. This study used qualitative research methods. The subjects of this study were search results that were not optimal in PLTS $15 \mathrm{kWp}$ on Sabira Island. The data analysis technique used is descriptive analysis with data collection techniques, namely field observations. The results of the study indicated that the 15 $k W p$ PLTS on Sabira Island was deactivated (not charged). This is because the optimal performance of PLTS 15 $k W p$ which is caused by damage to some components inside. The conclusion of this study is the factors that cause no optimal photovoltaic output system on PLTS $15 \mathrm{kWp}$ are differences in the character of 4 solar modules on 2 strings, shading, snail track, hot spot and dust buildup on solar modules, incompatible interconnections and damage to inverter modules due to lack of maintenance and regular monitoring of the components of the PLTS. This shows that the importance of periodic maintenance and monitoring of all components of PLTS.
\end{abstract}

Keywords: PLTS, Sabira Island, Damage, Component, Monitoring.

\begin{abstract}
Abstrak
Tujuan dari penelitian ini adalah mengetahui faktor penyebab tidak optimalnya dan sistem kerja dari PLTS 15 kWp sebagai pembangkit listrik di Pulau Sabira. Penelitian ini menggunakan metode penelitian kualitatif. Subjek dari penelitian ini adalah pencarian penyebab tidak optimalnya kinerja PLTS $15 \mathrm{kWp}$ di Pulau Sabira. Teknik analisis data yang digunakan yaitu analisis deskriptif dengan teknik pengumpulan data yaitu observasi lapangan. Hasil penelitian menujukan bahwa PLTS $15 \mathrm{kWp}$ di Pulau Sabira dalam keadaan dinonaktifkan (tidak dikebebankan). Hal ini karena tidak optimalnya kinerja PLTS $15 \mathrm{kWp}$ yang disebabkan oleh kerusakan pada beberapa komponen di dalamnya. Kesimpulan dari penelitian ini adalah faktor - faktor yang menyebabkan tidak optimalnya photovoltaic output system pada PLTS $15 \mathrm{kWp}$ adalah perbedaan karakter 4 modul surya pada 2 string, shading, snail track, hot spot serta penumpukan debu pada modul surya, interkoneksi yang tidak kompatibel dan kerusakan pada modul inverter akibat dari kurangnya perawatan serta monitoring secara teratur terhadap komponen-komponen PLTS tersebut. Hal ini menunjukan bahwa pentingnya perawatan dan monitoring secara berkala terhadap seluruh komponen PLTS.
\end{abstract}

Kata Kunci: PLTS, Pulau Sabira, Kerusakan, Komponen, Monitoring.

\section{PENDAHULUAN}

Sejak beberapa abad yang lalu manusia mulai menjadi mahkluk yang sangat bergantung kepada bahan bakar fosil seperti minyak, batubara, dan gas alam. Dari kendaraan bermotor, mesin-mesin industri, dan kebutuhan akan energi listrik yang sebagian besar dihasilkan dari Pembangkit Listrik Tenaga Diesel, mulai pada saat itulah bahan bakar minyak (BBM) menjadi salah satu kebutuhan manusia. Dalam laporan bertajuk "Prospek Populasi Dunia" (Markas Besar PBB: Revisi 2012, New York, Amerika Serikat) disebutkan bahwa penduduk dunia akan meningkat menjadi 8,1 miliar jiwa pada tahun 2025 dari 7,2 miliar jiwa jumlah pada tahun 2012. Jumlah itu akan terus meningkat menjadi 9,6 miliar jiwa pada tahun 2050, yang sebelumnya diprediksi hanya mencapai 9,3 miliar jiwa.

Di zaman modern, energi listrik merupakan kebutuhan umat manusia yang sangat penting dan vital serta tidak dapat dilepaskan dari kehidupan sehari-hari, tersedianya energi listrik dalam jumlah yang cukup akan menjadi syarat bagi suatu umat manusia untuk memiliki taraf kehidupan yang lebih baik. Perkembangan industri yang maju, dan meningkatnya penggunaan energi listrik dapat dijadikan indikator meningkatnya kemakmuran suatu masyarakat. Indonesia adalah negara yang dilintasi oleh garis khatulistiwa, berada diantara dua benua, yaitu Benua Asia dan Benua Afrika, dan berada diantara dua samudra yaitu Samudra Pasifik dan Samudra Hindia. Indonesia merupakan negara dengan kepulauan terbesar di duia, terdiri dari 17.504 pulau (Eko PrasetyaMerdeka:2017. Dengan populasi hampir 270.054.853 jiwa pada tahun 2018 (Biro Pusat Statistik-Jakarta: 2018)

Tercatat selama bulan Januari - Maret tahun 2018 konsumsi listrik di Indonesia mencapai 55,42 Tera Watt Hour (TWh), terdiri dari 
konsumsi sektor bisnis sebesar 9,9 TWh, industri sebesar 18,5 TWh, dan rumah tangga sebesar 22,9 TWh (Yuddy Setyo WicaksonoKepala Niaga PLN: 2018).

Pada saat ini sumber BBM telah mencapai pada kondisi dimana pengguna lebih banyak daripada ketersediaanya, dengan itu pemerintah Indonesia mengupayakan pengurangan dari penggunaan BBM. Salah satunya dengan berkomitmen untuk meningkatkan pemanfaatan sumber energi domestik diantaranya adalah gas bumi. Cadangan yang dimiliki oleh gas bumi sebagai energi domestik sebesar 142.72 Triliun Standart Cubic Feet sebagai energi bersih dan ramah lingkungan. Melalui PP No.79 Th.2014 tentang Kebijakan Energi Nasional, pemanfaatan gas bumi domestik ditargetkan meningkat dari tahun 2014 sebesar $19 \%$ menjadi $24 \%$ pada tahun 2050.

Sebaliknya, pemanfaatan minyak bumi diturunkan dari tahun 2014 sebesar 42\% menjadi $20 \%$ pada tahun 2050. Selain itu masih banyak cara untuk menurunkan penggunaan BBM, salah satunya adalah dengan mulai mengembangkan teknologi energi bebas terbarukan untuk dapat menghasilkan energi listrik. Salah satunya adalah pemanfaatan energi fotovoltaik dengan panel surya, dimana energi surya dirubah menjadi energi listrik atau biasanya dikenal dengan PLTS.

Pulau Sabira adalah salah satu kepulauan terluar paling utara di DKI Jakarta, luas pulau ini ( \pm ) 8,5 Hektar, pulau ini dihuni oleh 160 Kepala Keluarga atau sekitar 580 jiwa dengan 144 bangunan yang ada pada tahun 2019. Kebutuhan energi listrik di pulau ini tidak dapat dijangkau oleh aliran listrik dari PLN secara langsung. Hal ini dikarenakan jarak tempuh yang bisa sampai 8 jam perjalanan dengan kapal nelayan, tidak adanya kapal yang beroperasi sebagai sarana transportasi umum disana menjadi kendala paling besar untuk segala pemenuhan kebutuhan masyarakat pulau tersebut. Terutama adalah pasokan energi listrik, pulau ini hanya bisa memanfaatkan energi listrik dengan bersumber dari PLTD, PLTD ini beroperasi dari pukul 16.30-06.30 WIB saja.
Sejak tahun 2012 mulailah dibangun pembangkit listrik lainnya dengan konsep pemanfaatan energi alternatif terbarukan, yaitu dibangunnya PLTS disana. Hal ini menjadi salah satu solusi terbaru pasokan energi listrik di pulau ini, namun semakin bertambah tahun semakin bertambah pula penduduk serta pembangunan serta fasilitas umum disana, tentu hal tersebut menjadi masalah terbaru dengan kebutuhan energi listrik yang lebih besar dan akan semakin bertambah seiring berjalannya waktu.

\section{METODE PENELITIAN}

Metode penelitian yang digunakan adalah metode pendekatan kualitatif, dimana lebih menekankan pada aspek pemahaman secara mendalam terhadap suatu masalah dari pada melihat permasalahan untuk penelitian generalisasi.

\section{HASIL DAN PEMBAHASAN}

Penelitian pertama dengan melakukan pengecekan secara fisik pada 4 komponen penting dalam PLTS:

1. Hasil pengecekan modul surya secara fisik pada PLTS $15 \mathrm{kWp}$ dengan sistem off-grid.

Tabel 4.1. Hasil Pengecekan Modul Surya

\begin{tabular}{|c|c|c|c|c|c|c|}
\hline \multirow{2}{*}{ No } & \multirow{2}{*}{ Keterangan } & \multicolumn{2}{|c|}{ Kondisi } & \multicolumn{2}{|c|}{ Saran } & \multirow{2}{*}{ Kesimpulan } \\
\hline & & Baik & Tidak & Perbaikan & Pergantian & \\
\hline & Struktur & & & & & Masih \\
\hline \multirow[t]{2}{*}{1.} & Penopang & v & & & & kokoh \\
\hline & & & & & & Masih \\
\hline \multirow[t]{2}{*}{2.} & Pondasi & v & & & & kokoh \\
\hline & Kemiringan & & & & & \\
\hline \multirow[t]{3}{*}{3.} & Modul & v & & & & $15^{\circ} \mathrm{LU}$ \\
\hline & & & & & & $\geq 50 \mathrm{~cm}$ \\
\hline & Ketinggian & & & & & (tidak terlalu \\
\hline \multirow[t]{7}{*}{4.} & Modul & $\mathrm{v}$ & & & & rendah) \\
\hline & & & & & & Beberapa \\
\hline & & & & & & daun \\
\hline & & & & & & pepohonan \\
\hline & Bayangan & & & & & menghalangi \\
\hline & Benda & & & & & sinar \\
\hline & (Shading) & & & & & matahari \\
\hline 5. & Pada Modul & & v & v & & datang \\
\hline & Bingkai & & & & & \\
\hline \multirow[t]{3}{*}{6.} & Modul & v & & & & Masih utuh \\
\hline & Kaca & & & & & Beberapa \\
\hline & Pelindung & & & & & terjadi \\
\hline \multirow[t]{4}{*}{7.} & Modul & $\mathrm{v}$ & & & & keretakan \\
\hline & Lembar & & & & & \\
\hline & insulasi & & & & & \\
\hline & (backsheet) & & & & & \\
\hline \multirow[t]{3}{*}{8.} & Modul & $\mathrm{v}$ & & & & Masih utuh \\
\hline & & & & & & Masih utuh \\
\hline & Junction & & & & & dan tertutup \\
\hline \multirow[t]{4}{*}{9.} & Box & v & & & & dengan baik \\
\hline & & & & & & Terdapat \\
\hline & & & & & & hot spot di \\
\hline & Sel & & & & & beberapa sel \\
\hline 10. & Fotovoltaik & & v & & v & fotovoltaik \\
\hline
\end{tabular}




\begin{tabular}{|c|c|c|c|c|c|c|}
\hline & Label Kabel & & & & & Beberapa \\
\hline & Antar & & & & & copot dan \\
\hline \multirow[t]{3}{*}{11.} & Modul & & v & & v & perlu digant \\
\hline & & & & & & Masih \\
\hline & Dioada & & & & & \\
\hline \multirow[t]{4}{*}{12.} & Bypass & r & & & & $(10 \mathrm{~m} \Omega)$ \\
\hline & & & & & & Terjadi \\
\hline & & & & & & keretakan d \\
\hline & Kaca & & & & & beberapa \\
\hline \multirow[t]{5}{*}{13.} & Fotovoltaik & & v & & v & modul \\
\hline & & & & & & Terdapat \\
\hline & & & & & & beberapa \\
\hline & & & & & & ketidak \\
\hline & Interkoneksi & & & & & standaran \\
\hline \multirow[t]{3}{*}{14.} & Modul & & v & & v & instalasi \\
\hline & & & & & & Memiliki \\
\hline & Jarak Antar & & & & & jarak yang \\
\hline \multirow[t]{5}{*}{15.} & Modul & r & & & & cukup \\
\hline & & & & & & Terdapat \\
\hline & & & & & & beberapa \\
\hline & & & & & & modul \\
\hline & Temperatur & & & & & terkena hot \\
\hline \multirow[t]{2}{*}{16.} & Modul & & v & & v & spot \\
\hline & & $\mathbf{a b}$ & 4.1 & (Lanjl & an) & \\
\hline \multirow[t]{2}{*}{ No } & Keterangan & \multicolumn{2}{|c|}{ Kondisi } & \multicolumn{2}{|c|}{ Saran } & Kesimpulan \\
\hline & & Baik & Tidak & Perbaikan & Pergantian & \\
\hline & & & & & & Tidak ada \\
\hline & & & & & & modul \\
\hline & & & & & & yang \\
\hline & Komposisi & & & & & terhalangi \\
\hline & Modul di & & & & & oleh \\
\hline & Dalam & & & & & bayangan \\
\hline \multirow[t]{5}{*}{17.} & Rangkaian & v & & & & modul lain \\
\hline & & & & & & Tidak \\
\hline & & & & & & memakai \\
\hline & & & & & & spiral / \\
\hline & Pemasangan & & & & & duct kabel \\
\hline \multirow[t]{2}{*}{18.} & Kabel & & v & & v & \\
\hline & Tiang & & & & & Masih \\
\hline \multirow[t]{2}{*}{19.} & Penopang & v & & & & kokoh \\
\hline & & & & & & Masih \\
\hline 20. & Pelat Dasar & v & & & & kokoh \\
\hline
\end{tabular}

2. Hasil pengecekan SCC secara fisik pada PLTS $15 \mathrm{kWp}$ dengan sistem off-grid. Tabel 4.2. Hasil Pengecekan SCC

\begin{tabular}{|c|c|c|c|c|c|c|}
\hline \multirow{2}{*}{ No } & \multirow{2}{*}{ Keterangan } & \multicolumn{2}{|c|}{ Kondisi } & \multicolumn{2}{|c|}{ Saran } & \multirow{2}{*}{ Kesimpulan } \\
\hline & & Baik & Tidak & Perbaikan & Pergantian & \\
\hline & & & & & & $\begin{array}{l}\geq 20 \mathrm{~cm} \\
\text { (terdapat } \\
\text { ruang } \\
\text { untuk }\end{array}$ \\
\hline & Jarak antar & & & & & sirkulasi \\
\hline \multirow[t]{2}{*}{1.} & $\mathrm{SCC}( \pm 20 \mathrm{~cm})$ & v & & & & udara) \\
\hline & Label Pada & & & & & Masih \\
\hline \multirow[t]{2}{*}{2.} & SCC & v & & & & utuh \\
\hline & Temp. & & & & & \\
\hline \multirow[t]{2}{*}{3.} & $\left(<35^{\circ} \mathrm{C}\right)$ & v & & & & $28,8^{\circ} \mathrm{C}$ \\
\hline & Temp. SCC & & & & & Dalam \\
\hline \multirow[t]{2}{*}{4.} & $\left(<45^{\circ} \mathrm{C}\right)$ & v & & & & kondisi off \\
\hline & Instalasi & & & & & Memakai \\
\hline \multirow[t]{2}{*}{5.} & Kabel SCC & v & & & & duct kabel \\
\hline & Layar & & & & & Kondisi \\
\hline \multirow[t]{2}{*}{6.} & Informasi & v & & & & baik \\
\hline & & & & & & Kondisi \\
\hline \multirow[t]{2}{*}{7.} & Gland Kabel & v & & & & baik \\
\hline & & & & & & Kondisi \\
\hline \multirow[t]{2}{*}{8.} & Kabel Daya & v & & & & baik \\
\hline & Kabel & & & & & Kondisi \\
\hline \multirow[t]{2}{*}{9.} & Komunikasi & v & & & & baik \\
\hline & Terminator & & & & & Kondisi \\
\hline \multirow[t]{2}{*}{10.} & Jaringan & v & & & & baik \\
\hline & Sensor & & & & & Tidak \\
\hline \multirow[t]{2}{*}{11.} & Temp.Baterai & & $\mathrm{v}$ & v & & terpasang \\
\hline & Nomor & & & & & Kondisi \\
\hline 12. & Identifikasi & $\mathrm{v}$ & & & & baik \\
\hline
\end{tabular}

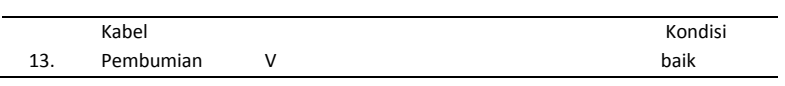

3. Hasil pengecekan inverter secara fisik pada PLTS $15 \mathrm{kWp}$ dengan sistem off-grid. Tabel 4.3. Hasil Pengecekan Inverter

\begin{tabular}{|c|c|c|c|c|c|c|}
\hline \multirow{3}{*}{ No } & \multirow{3}{*}{ Keterangan } & \multicolumn{2}{|c|}{ Kondisi } & \multicolumn{2}{|c|}{ Saran } & \multirow{3}{*}{$\begin{array}{c}\text { Kesimpul } \\
\text { an }\end{array}$} \\
\hline & & & Tida & Perbaik & Perganti & \\
\hline & & Baik & $\mathrm{k}$ & an & an & \\
\hline \multirow{5}{*}{1.} & & & & & & Terdapat \\
\hline & Kisi & & & & & di bagian \\
\hline & Ventilasi & V & & & & atas \\
\hline & & & & & & 1 \\
\hline & Tampilan & & & & & inverter \\
\hline \multirow[t]{3}{*}{2.} & Informasi & & V & & V & mati \\
\hline & & & & & & Memaka \\
\hline & Kompartem & & & & & i duct \\
\hline \multirow[t]{5}{*}{3.} & en Kabel & v & & & & kabel \\
\hline & & & & & & Beberap \\
\hline & Rating & & & & & a label \\
\hline & Ingress & & & & & sudah \\
\hline & Protection & & & & & tidak \\
\hline \multirow[t]{2}{*}{4.} & $(>\mathrm{P} 40)$ & v & & & & terbaca \\
\hline & Jarak antar & & & & & Cukup \\
\hline 5. & Inverter & v & & & & luas \\
\hline
\end{tabular}

\begin{tabular}{|c|c|c|c|c|c|c|}
\hline \multicolumn{7}{|c|}{ Tabel 4.3. (Lanjutan) } \\
\hline \multirow[t]{2}{*}{ No } & \multirow[t]{2}{*}{ Keterangan } & \multicolumn{2}{|c|}{ Kondisi } & \multicolumn{2}{|c|}{ Saran } & \multirow[t]{2}{*}{ Kesimpulan } \\
\hline & & Baik & Tidak & Perbaikan & Pergantian & \\
\hline & Temp. & & & & & \\
\hline & Ruangan & & & & & \\
\hline \multirow[t]{3}{*}{6.} & $\left(>35^{\circ} \mathrm{C}\right)$ & v & & & & $28,9^{\circ} \mathrm{C}$ \\
\hline & Struktur & & & & & \\
\hline & Penopang & & & & & Langsung \\
\hline \multirow[t]{3}{*}{7.} & Inverter & v & & & & ke lantai \\
\hline & & & & & & Memakai \\
\hline & Instalasi & & & & & duct kabel \\
\hline \multirow[t]{2}{*}{8.} & Kabel & v & & & & \\
\hline & Kabel & & & & & Memakai \\
\hline \multirow[t]{2}{*}{9.} & Komunikasi & v & & & & duct kabel \\
\hline & & & & & & Memakai \\
\hline \multirow[t]{5}{*}{10.} & Kabel Daya & v & & & & duct kabel \\
\hline & Koneksi & & & & & \\
\hline & Terminal & & & & & \\
\hline & Baterai & & & & & \\
\hline & pada & & & & & Kondisi \\
\hline \multirow[t]{2}{*}{11.} & Inverter & $\mathrm{v}$ & & & & baik \\
\hline & & & & & & Kondisi \\
\hline \multirow[t]{2}{*}{12.} & Gland Kabel & v & & & & baik \\
\hline & & & & & & Kondisi \\
\hline \multirow[t]{3}{*}{13.} & ID Inverter & v & & & & baik \\
\hline & Sensor & & & & & \\
\hline & Temperatur & & & & & Tidak \\
\hline \multirow[t]{3}{*}{14.} & Baterai & & v & & & terpasang \\
\hline & Koneksi & & & & & \\
\hline & Pembumian & & & & & Kondisi \\
\hline 15. & pada Casis & v & & & & baik \\
\hline
\end{tabular}

4. Hasil pengecekan baterai secara fisik pada PLTS $15 \mathrm{kWp}$ dengan sistem off-grid.

Tabel 4.4. Hasil Pengecekan Baterai

\begin{tabular}{|c|c|c|c|c|c|c|}
\hline \multirow{2}{*}{ No } & \multirow{2}{*}{ Keterangan } & \multicolumn{2}{|c|}{ Kondisi } & \multicolumn{2}{|c|}{ Saran } & \multirow{2}{*}{ Kesimpulan } \\
\hline & & Baik & Tidak & Perbaikan & Pergantian & \\
\hline & Terminal & & & & & \\
\hline 1. & $\begin{array}{l}\text { Positif } \\
\text { Terminal }\end{array}$ & v & & & & Kondisi baik \\
\hline 2. & $\begin{array}{l}\text { Negatif } \\
\text { Peletakan }\end{array}$ & v & & & & Kondisi baik \\
\hline 3. & Baterai & v & & & & Kondisi baik \\
\hline
\end{tabular}




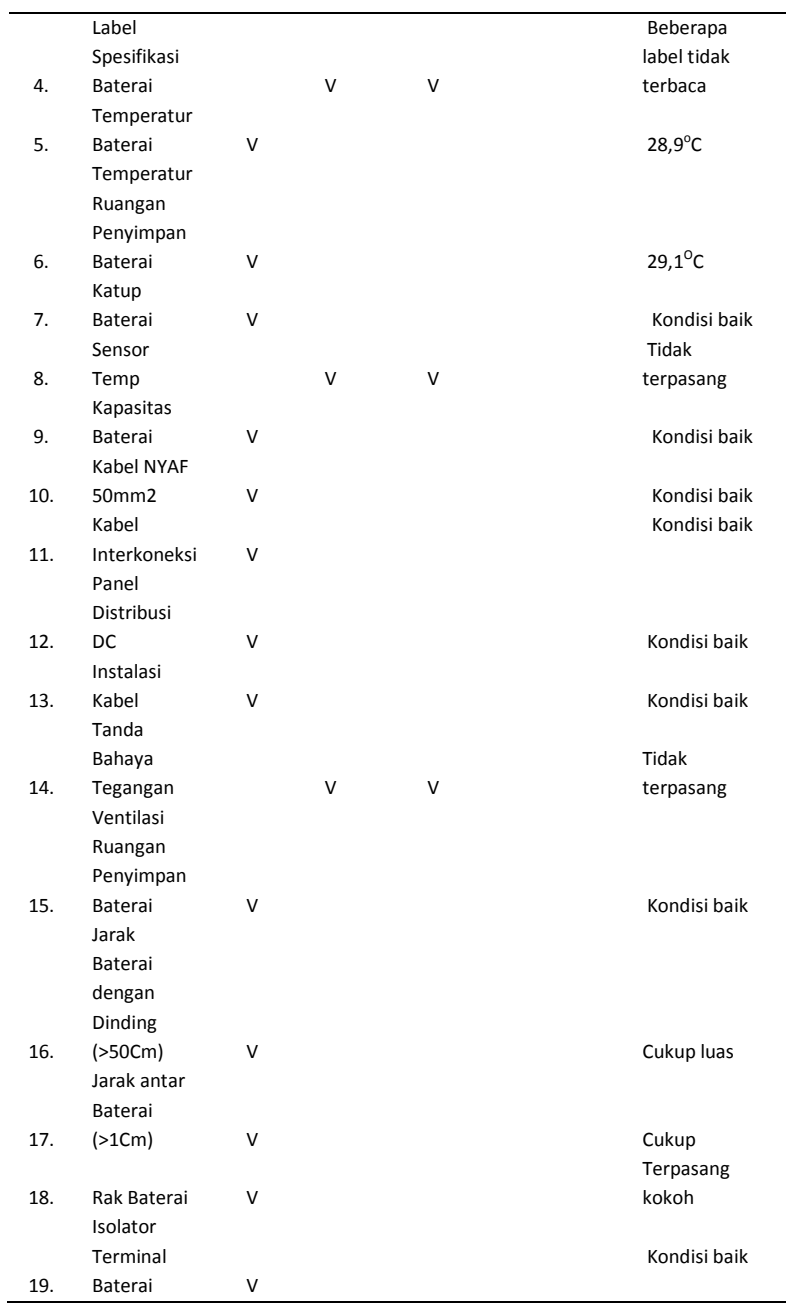

Hasil Pengukuran Photovoltaic output system Modul Surya pada Panel Combiner

Penelitian kedua dengan melakukan pengukuran photovoltaic output system modul surya pada panel combiner. Pengukuran dilakukan menggunakan 1 buah alat ukur "Digital Clampmeter (Kyoritsu tipe 2009R)", pengukuran dilakukan pada kondisi pick time selama 3 hari berturut-turut:
1. Hasil pengukuran panel combiner 1

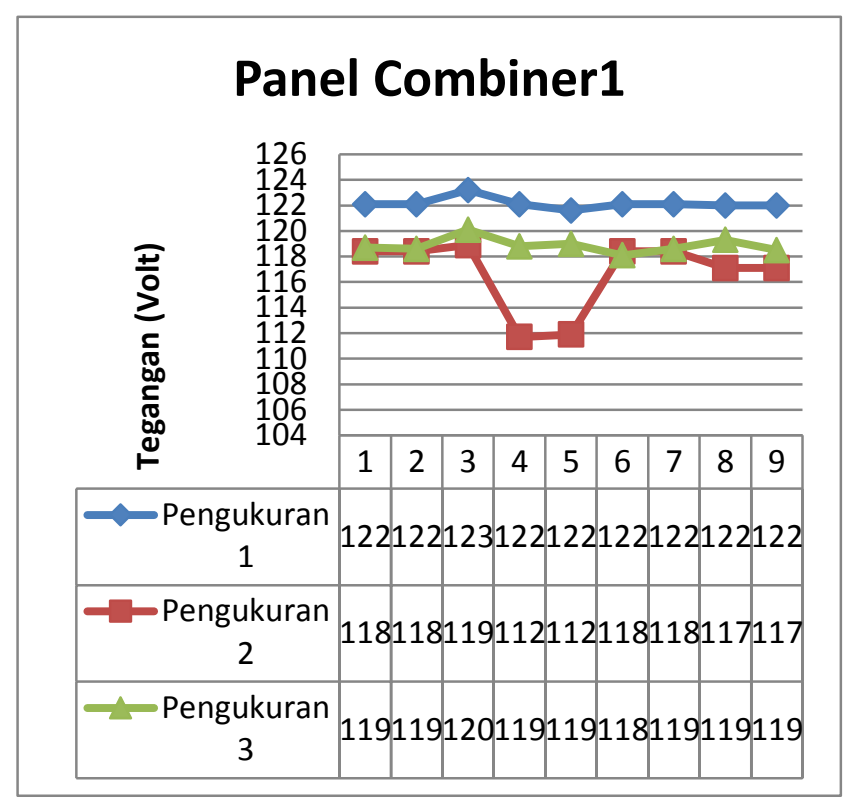

Gambar 4.1. Grafik Perbandingan Pengukuran Tegangan pada Panel Combiner 1 2. Hasil pengukuran panel combiner 2

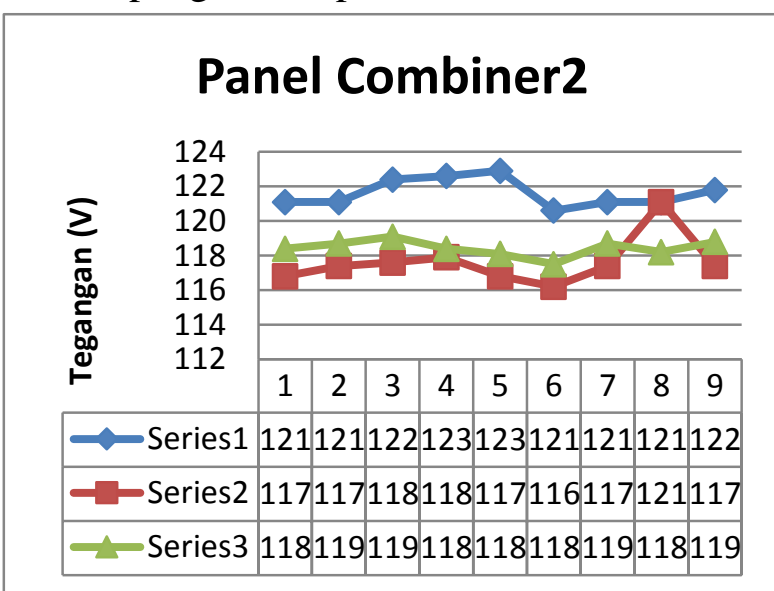

Gambar 4.2. Grafik Perbandingan Pengukuran Tegangan pada Panel Combiner 2 
3. Hasil pengukuran panel combiner 3

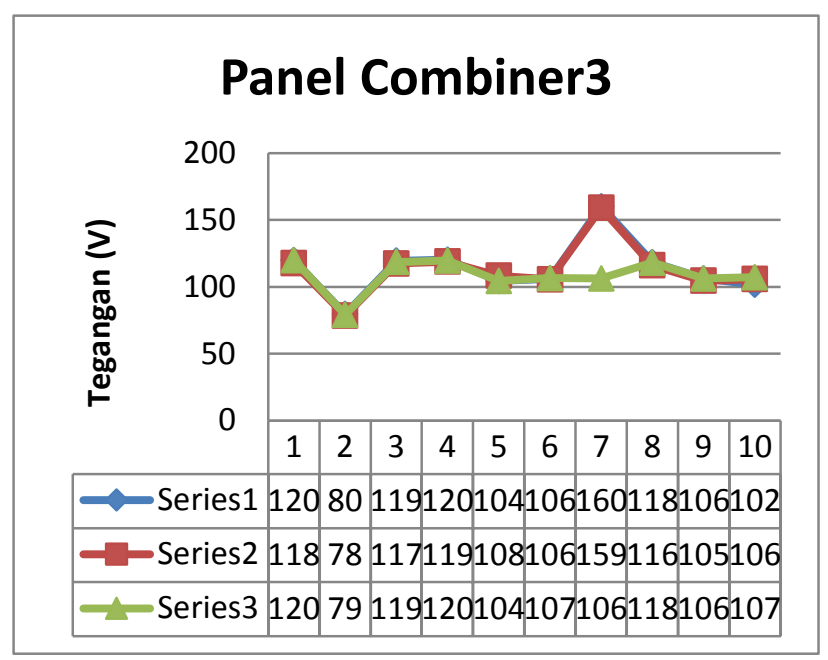

Gambar 4.3. Grafik Perbandingan

Pengukuran Tegangan pada Panel Combiner 3

PLTS ini dibangun dengan kapasitas $15 \mathrm{kWp}$ pada tahun 2012, PLTS ini diperuntukan untuk menyuplai 117 rumah, setelah melalui pengecekan dan pengukuran pada 4 komponen utama PLTS:

\section{Modul Surya}

Terdapat 84 buah modul surya dengan tipe LEN-180Wp (modul lama), dan telah dilakukan pergantian sebanyak 4 modul surya dengan tipe SPU-180M (modul baru). Dari tipe modul surya tersebut berarti modul surya lama dapat menghasilkan daya maksimal sebesar $180 \mathrm{Wp}$, sedangkan modul baru dapat menghasilkan daya maksimal sebesar 200Wp. Beberapa hal yang perlu diperhatikan:

- Dalam 28 string modul surya (3 buah modul surya dirangkai secara seri disebut string) terdapat 2 string modul surya dengan komposisi modul surya yang berbeda, hal ini dapat mengakibatkan daya yang dihasilkan modul surya menurun.

- Total modul surya adalah 84 buah, disusun menjadi 3 larik modul surya (gabungan beberapa string modul surya yang terhubung secara paralel), dalam pembagiannya larik 1 terdapat 9 string, larik 2 terdapat 9 string, larik 3 terdapat 10 string modul surya. Terdapat beberapa shading yang menutupi permukaan dari modul surya akan berpengaruh pada kondisi modul surya. Pelepasan panas pada sel yang terkena shading akan cenderung meningkat (hot spot) atau bisa disebut sebagai titik panas.

- Terjadi beberapa keretakan pada modul surya, keretakan ini apabila tidak diganti akan membuat kelembaban, oksigen, dan air masuk kedalam sel modul surya yang mengakibatkan hubungan arus pendek (penurunan kinerja/produksi dari modul surya)

- Interkoneksi atau instalasi modul surya masih belum sesuai dengan standar, masih banyak terdapat penyambungan kabel menggunakan terminal jenis sekrup. Hal ini akan menyebabkan terjadinya busur listrik, panas berlebih, bahaya sengatan listrik, dan resiko kebakaran (disarankan menggunakan konektor MC4 dengan hambatan $400 \Omega$ ).

\section{Solar Charge Controller (SCC)}

Terpasang 3 buah SCC "Solarcon SCB-4880 dengan sistem MPPT", dimana sistem ini lebih efisien karena pada sistem ini daya lebih yang tidak terpakai oleh beban dapat diteruskan dan disimpan kedalam baterai, dan apabila daya yang dibutuhka oleh beban lebih besar dari daya yang dihasilkan oleh modul surya maka daya dapat ditambah dari penyimpanan tersebut.

- Dalam pemasangan sudah menggunakan cable gland yang berfungsi untuk melindungi kabel dari kontak langsung antara kabel dengan tepi yang tajam dan mencegah binatang atau benda lainnya masuk kedalam SCC.

- Terpasangnya konduit kabel yang berfungsi untuk melindungi kabel dari gangguan lingkungan.

- SCC ini dirangkai secara paralel dengan bank baterai.

- Layar informasi masih terlihat dengan jelas, layar ini berfungsi untuk memudahkan operator melakukan monitoring secara berkala.

- PLTS ini dalam kondisi dinonaktifkan (tidak dikebebankan), namun dalam hal ini SCC akan tetap bekerja sesuai dengan fungsinya, yaitu mengatur masuknya tegangan dan arus dari modul surya kedalam proses pengisian baterai, serta memotong tegangan dan arus apabila penyimpanan didalam baterai sudah mencapai full charging.

- Tidak terdapat battery temperature sensor pada SCC, sensor ini berfungsi untuk mengatur tegangan charging yang disesuaikan dengan temperature dari baterai (optimum charging dan optimum usia baterai).

\section{Inverter}

Terpasang 3 buah inverter dengan tipe "Apollo S-210p" yang dirangkai secara paralel dan menghasilkan daya output total sebesar 15 
kWp. Beberapa hal yang perlu diperhatikan:

- Terdapat kisi ventilasi pada setiap inverter yang berfungsi untuk membuang udara panas dari dalam inverter, apabila terjadi peningkatan panas maka akan berpengaruh pada daya output.

- Terdapat 1 buah inverter yang mengalami kerusakan pada modul inverter.

- Pemasangan instalasi kabel inverter sudah sesuai dengan standar (menggunakan duct cable).

- Mode pada inverter tersebut menggunakan mode operasi berdiri sendiri (stand alone) atau off-grid.

- Pembumian pada casis terpasang dengan baik, hal ini berfungsi untuk mengurangi bahaya terkena sengatan listrik pada saat terjadi gangguan.

- Terdapat Multi-cluster box yang bertujuan untuk membangun sistem multi-cluster serta untuk menggabungkan inverter - SCC - beban (multi-cluster box dihubungkan ke 3 inverter yang disusun secara paralel sebelum didistribusikan ke jaringan distribusi).

- Tidak terdapat baterry temperature sensor.

- Pemasangan inverter sudah sesuai dengan standar dengan tidak melebihi jarak maksimal dari bank baterai ke inverter ( $\leq 10$ meter). Jakar antar inverter ini juga sangat membantu dalam proses pelepasan udara panas dari inverter tersebut.

- Inverter berada pada posisi no load atau tanpa beban, dimana inverter tersebut hanya merubah output modul surya (arus DC) menjadi arus AC yang diteruskan kedalam panel AC.

4. Baterai

Terdapat 48 buah baterai dengan kapasitas $1500 \mathrm{Ah} / 2 \mathrm{~V}$ pada setiap baterai. Dari total 48 buah baterai dibagi menjadi 2 bank baterai ( 24 buah baterai dalam 1 bank baterai dirangkai secara seri). Beberapa hal yang perlu diperhatikan:

- Terpasangnya terminal positif, terminal negatif, serta terdapat katup dengan kondisi baik. Katup ini berfungsi untuk mencegah kehilangan oksigen yang tidak perlu selama pengoperasian normal, dan akan mengurangi kapasitas baterai apabila katup tersebut bocor atau tidak terpasang dengan baik.
- Kerusakan pada katup menyebabkan kebocoran yang mengakibatkan bercampurnya hidrogen dan oksigen, apabila kandungan hidrogen di udara mencapai $4 \%$ maka akan beresiko terjadinya ledakan.

- Kondisi terminal baterai dalam keadaan baik dan terbebas dari korosi maupun kristal sulfida (senyawa kimia yang keluar dari baterai).

- Perbedaan antar baterai $\geq 3{ }^{\circ} \mathrm{C}$, maka dari itu disarankan memasang battery temperature sensor agar perubahan temperature termonitoring dengan baik.

- Kabel tidak terpasang dengan baik, dikarenakan tidak memakai konduit, hal ini untuk mengantisipasi kejadian yang tidak diinginkan.

- Kondisi bank baterai tersimpan dengan rapih didalam ruangan penyimpanan yang terdapat ventilasi untuk sirkulasi udara keluar dan masuk.

- Sel baterai juga dipasangkan dengan baik, yaitu dengan jarak yang cukup agar baterai apat melepaskan udara panas $(\geq 1 \mathrm{~cm})$.

5. Photovoltaic output system Modul Surya LEN-180Wp

Tabel 4.5. Photovoltaic output system Modul Surya LEN-180Wp

\begin{tabular}{cccc}
\hline KET & Hasil Pengukuran & Daya \\
& & & \\
& Vpm (V) & Ipm (A) & $P(\mathrm{Wp})$ \\
\hline $\begin{array}{c}\mathbf{1} \\
\text { Modul }\end{array}$ & 41,1 & 0,54 & 22,2 \\
$\mathbf{1}$ String & 118,5 & 4,9 & 580,6 \\
\hline
\end{tabular}

6. Photovoltaic output system Modul Surya SPU-180M

Tabel 4.6. Photovoltaic output system Modul Surya SPU-180M

\begin{tabular}{cccc} 
KET & Hasil Pengukuran & Daya \\
& Vpm (V) & Ipm $(\mathrm{A})$ & $P(\mathrm{Wp})$ \\
\hline $\begin{array}{c}\mathbf{1} \\
\text { Modul }\end{array}$ & 40,7 & 0,54 & 22 \\
$\mathbf{1}$ String & 121,2 & 4,9 & 593,9 \\
\hline
\end{tabular}


7. Daya Photovoltaic output system pada Panel Combiner

Tabel 4.7. Daya Photovoltaic output system Modul Surya SPU-180M

\begin{tabular}{cccc}
\hline & COMBINER & COMBINER & COMBINER \\
NO & 1 & 2 & 3 \\
STRING & $\begin{array}{c}\text { DAYA } \\
\text { TERUKUR } \\
\text { RATA-RATA } \\
\text { (Pout) }\end{array}$ & $\begin{array}{c}\text { DAYA } \\
\text { TERUKUR } \\
\text { RATA-RATA } \\
\text { (Pout) }\end{array}$ & $\begin{array}{c}\text { DAYA } \\
\text { TERUKUR } \\
\text { RATA-RATA } \\
\text { (Pout) }\end{array}$ \\
& $\begin{array}{c}\text { (Vpm.rerata } \\
\text { (Vpm.rerata }\end{array}$ & $\begin{array}{c}\text { (Vpm.rerata } \\
\text { (Vpm) }\end{array}$ & x Ipm) \\
\hline 1 & 586,7 & 415,7 & 405 \\
2 & 586,5 & 416,7 & 268,6 \\
3 & 591,6 & 418,9 & 402,8 \\
4 & 575,9 & 418,7 & 406,5 \\
5 & 575,7 & 417,4 & 359,4 \\
6 & 585,7 & 413,3 & 360,6 \\
7 & 586,5 & 416,7 & 482 \\
8 & 585,4 & 420,5 & 399,4 \\
9 & 584,1 & 417,7 & 359,1 \\
10 & & & 356,2 \\
\hline
\end{tabular}

\section{KESIMPULAN DAN SARAN}

\section{Kesimpulan}

Berdasarkan penelitian yang dilakukan pada PLTS 15 kWp di Pulau Sabira, berikut beberapa kesimpulan yang dapat diambil:

1. Nilai output tegangan modul surya LEN180Wp tidak berbeda jauh dengan nilai tegangan modul surya SPU-180M, sedangkan arus pada keduanya adalah sama. Hal ini disebabkan karena kedua modul surya tersebut dalam satu string yang sudah terhubung.

2. Nilai efisiensi daya modul surya rata-rata hanya mencapai angka $6,96 \%$, angka ini belum mencapai nilai efisiensi maksimal pada modul surya. Dimana nilai tersebut disebabkan karena 80 dari total 84 modul surya sudah memasuki tahun ke-7 dalam pemakaiannya.

3. Terdapat spesifikasi karakter modul surya yang berbeda dalam rangkaian PLTS $15 \mathrm{kWp}$ yang menyebabkan tidak optimalnya photovoltaic output system dari modul surya tersebut.

4. Terdapat shading, snail track, hot spot, dan penumpukan debu di beberapa modul surya karena kurangnya perawatan dari warga terhadap modul tersebut, serta mengakibatkan penurunan kinerja pada PLTS $15 \mathrm{kWp}$.

5. Terdapat penyambungan atau interkoneksi yang tidak kompatibel dalam rangkaian antar modul surya (seperti melakukan penyambungan antar modul menggunakan terminal sekrup dan lakban) mengakibatkan terjadinya rugi-rugi tegangan.

6. Akibat kurangnya perwatan berkala dan penanganan kerusakan secara cepat dan tepat pada PLTS $15 \mathrm{kWp}$ tersebut mengakibatkan banyak komponen yang menjadi lebih cepat usia pakainya.

7. Terpasangnya SCC dengan sistem MPPT (Maximum Power Point Tracking) lebih efektif dalam mengontrol pengisian baterai dari modul surya, karena dalam sistem ini pengisian baterai memanfaatkan kelebihan tegangan yang dikonversi menjadi arus yang lebih tinggi ke baterai.

8. Saat bank baterai dalam kondisi penuh mampu memenuhi kebutuhan listrik dengan beban 117 rumah selama 5,6 Jam.

\section{Saran}

Berdasarkan kesimpulan di atas maka dapat dikemukakan saran, agar PLTS $15 \mathrm{kWp}$ lebih optimal kinerjanya, sebagai berikut:

1. Ganti modul surya yang mengalami kerusakan dengan modul surya dari merk dan karakteristik yang sama.

2. Ganti inverter yang rusak dengan merk dan spesifikasi yang sama.

3. Atur ulang interkoneksi kabel, dan jika perlu kurangi panjang kabel untuk mengurangi rugi-rugi pada kabel.

4. Hindari kabel yang melingkar pada fasa positif dan fasa negatif dari kabel string modul surya, kabel harus sedekat mungkin agar terhindar dari tegangan induksi yang disebabkan ketika tersambar petir.

5. Gunakan konektor dengan jenis dan model yang sama agar terhindar dari ketidak cocokan yang menyebabkan koneksi menjadi buruk (rekomendasi konektor menggunakan konektor MC4)

6. Gunakan konduit kabel pada instalasi antar modul surya untuk membantu kabel agar tahan terhadap gerakan mekanis ketika angin bertiup kencang. 
7. Pasang battery temperature sensor agar mempermudah operator dalam monitoring, dari segi umur maupun optimum charging pada baterai.

8. Wajib dilakukan perawatan dan monitoring secara rutin agar dapat dilakukan tindakan pencegahan jika salah satu komponen PLTS ada yang menunjukan penurunan state of health.

9. Tambahkan tanda-tanda peringatan bahaya dan larangan di dalam ruangan rumah pembangkit.

10. Perlunya kesadaran masyarakat setempat dan dilakukannya sosialisasi masal kepada seluruh warga, tentang pentingnya perawatan PLTS maupun penggunaan energi secara umum.

11. Lakukan verifikasi dari setiap string modul surya untuk photovoltaic output system sesuai dengan yang diharapkan dan kesamaan tiap string modul surya pada saat proses commissioning.

\section{DAFTAR PUSTAKA}

Amelia, A. R. 2018. Konsumsi Listrik PLN Turun 46\% Sepanjang Semester I-2018. Retrieved from kadata: https://katadata.co.id/berita/2018/08/03/ko nsumsi-listrik-pln-turun-46-sepanjangsemester-i-2018[diakses 3 Agustus 2018]

Hasyim Asy'ari, J. A. 2012. Intensitas Cahaya Matahari terhadap Daya Keluaran Panel Sel Surya. Retrieved from publikasiilmiah.ums:

https://publikasiilmiah.ums.ac.id/bitstream /handle/11617/3930/E08.pdf?sequence=1 \&isAllowed $=\mathrm{y}$. Intensitas cahaya matahari terhadap daya keluaran panel sel surya, 53. [diakses 20 Agustus 2018]

Indonesia, S. S. 2012. Solar Charge Controller. Retrieved from solarsuryaindonesia: http://solarsuryaindonesia.com/info/solarcontroller[diakses 11 September 2018]

Katadata. 2018, Jumlah Penduduk Indonesia Mencapai 265 Juta Jiwa. Retrieved from databoks.kadata: https://databoks.katadata.co.id/datapublish /2018/05/18/2018-jumlah-penduduk- indonesia-mencapai-265-juta-jiwa[diakses 3 Agustus 2018]

LEONICS. (n.d.). LEONICS. Retrieved from www.leonics.com:

https://www.leonics.com/product/renewab le/inverter/inverter_apollo_s-

210p_en.php[diakses 27 April 2019]

Leonics. 2011. Leonics Solarcon SCB.

Retrieved from www.minhha.vn: http://www.minhha.vn/catalogue/SCB-

151.pdf[diakses 27 April 2019]

Media, K. C. 2013. Pertumbuhan Penduduk

Dunia Lampaui Prediksi. Retrieved from internasional:

https://internasional.kompas.com/read/201 3/06/15/10091516/Pertumbuhan.Pendudu

k.Dunia.Lampaui.Prediksi[diakses 3 Agustus 2018]

Muslich, M. 2018. Instalasi Pembangkit Listrik Tenaga Surya Dos \& Don'ts. Jakarta: Energising Development.

Prasetya, E. 2017. Dari 17.504 Pulau di Indonesia, 16.056 telah diverifikasi PBB. Retrieved from merdeka: https://www.merdeka.com/peristiwa/dari17504-pulau-di-indonesia-16056-telahdiverifikasi-pbb.html[diakses 11 Agustus 2018]

Technologies, F. 2007. FIAMM SMG $(O P z V)$ ENDURLITE VRLA range. Retrieved from www.p-s-s.com: https://www.p-ss.com/PDF/Endurlite_SMG.pdf[diakses 27 April 2019]

Wardani, R. 2017. Yang muda, yang cerita. Retrieved from ebtke.esdm: http://ebtke.esdm.go.id/post/2017/09/15/1 748/yang.muda.yang.cerita[diakses 21 Agustus 2018] 